Methods A multi-stakeholder team updated the form and processes with user feedback. Improvements included:

- rewriting and expanding symptom management guidance

- providing a starting 'recipe' of anticipatory medicines that can be adjusted to individualise care

- an electronic version of the CD1 form including options to integrate into SystmOne and EMIS

- the ability to tailor the CD1 form for local prescriber preference

- additional resources including formularies for SystmOne and EMIS

- making all resources openly available on www.eolc.co.uk

Evaluation The updated CD1 form and resources were published in May 2018. Its use is being promoted alongside encouraging associated behavioural change within Lincolnshire around anticipatory prescribing. Initial feedback around clarity and ease of use is positive suggesting the revised CD1 form has addressed previous barriers around its use.

Next steps Formal user feedback survey. Data is to be collected from out of hours providers pre- and post- implementation to evaluate if the new process results in a reduction in calls to these services for symptom management in dying patients.

\section{P-121 A NEW ANTI-EMETIC: OLANZAPINE FOR THE PREVENTION AND TREATMENT OF CANCER-RELATED NAUSEA AND VOMITING}

\footnotetext{
${ }^{1,2}$ Anna Sutherland, ${ }^{1}$ Katrien Naessens, ${ }^{2}$ Emma Plugge, ${ }^{2}$ Martin Burton, ${ }^{2}$ Lynda Ware, ${ }^{2}$ Karen Head, ${ }^{3}$ Bee Wee. ${ }^{1}$ Sue Ryder Nettlebed, Oxfordshire, UK; ${ }^{2}$ Cochrane UK, Oxford, UK; ${ }^{3}$ Sir Michael Sobell House, Oxford, UK
}

\subsection{6/bmjspcare-2018-hospiceabs. 146}

We undertook a new Cochrane Systematic Review to assess the efficacy and safety of oral olanzapine when used as an anti-emetic in the prevention and treatment of nausea and vomiting related to cancer in adults. We searched published and unpublished trials up to the 8th September 2017. We included randomised controlled trials (RCTs) of olanzapine with or without adjunct therapies for the prevention and/or treatment of nausea or vomiting in patients with cancer aged 18 or over, in any setting, with $\geq 10$ participants per treatment arm. Standard Cochrane methodology was used.

We included 14 RCTs (1917 participants) from high, middle and low income countries in which olanzapine was administered orally, in people with over 24 different cancers, none of which were funded by pharmaceutical companies. Participants received: highly emetogenic (HEC) or moderately emetogenic (MEC) chemotherapy (12 studies); chemoradiotherapy (one study); or no active treatment (one study). Eight studies await classification and 13 are ongoing. The majority of studies were at low or unclear risk of bias across most domains. A high risk of bias, related to issues of blinding, was present in 10 RCTs.

Oral olanzapine probably almost doubles the likelihood of freedom from nausea and vomiting during chemotherapy from $25 \%$ to $50 \%$ (RR 1.98 , 95\% CI 1.59 to 2.47 ; 561 participants; solid tumours; HEC or MEC therapy; moderate quality evidence) when added to standard therapy. Number Needed to Treat for additional benefit (NNTB) was 5 (95\% CI 3.36.6). Serious concerns have been raised regarding the efficacy and safety of injectable olanzapine (intravenous, intramuscular or subcutaneous). Olanzapine probably increases somnolence and fatigue compared to no treatment or placebo (RR 2.33, 95\% CI 1.30 to 4.18 ; anticipated absolute risk $8.2 \%$ more). It is unclear if anti-emetic efficacy differs between $5 \mathrm{mg}$ and $10 \mathrm{mg}$ doses.

\section{P-122 EMBRACING INFORMAL CARERS AS PART OF THE HEALTHCARE TEAM}

'Vanessa Gibson, 'Sophie Edmonds, ${ }^{2}$ Carole Roberson. 'St Richard's Hospice, Worcester, Worcestershire; ${ }^{2}$ Worcestershire Health and Care Trust, Worcester, Worcestershire

\subsection{6/bmispcare-2018-hospiceabs.147}

The aim of this project is to empower patients and families to take an active role in symptom control at end of life. A multiprofessional team has been working together to develop a policy which will enable informal carers to administer as required subcutaneous medication at end of life. This project has been informed and guided by patients and carers. The rationale for this project is to:

- Enhance symptom control by more rapid administration of as required injectable medication, potentially enabling patients to remain at home

- To support and empower family members who want to provide this type of support to the patient, ensuring underpinning training and education is in place

- To complement rather than replace existing services, district nursing support will continue to be required

- To have a positive impact upon bereavement, enabling families to feel that they have done all that they can do for their loved one.

We have faced multiple challenges in developing this policy not least professional concerns relating to prescribing medication which will be administered by an informal carer and the professional implications of supporting informal carers to administer the prescribed medication. Initially it was hoped that this project would include the acute sector but this has been too difficult to achieve. Careful multiprofessional working has been critical.

We now have support to proceed from Worcestershire Clinical Commissioning Group, St Richard's Hospice and a General Practitioner (GP) locality team. An outline paper, inclusion/ exclusion criteria and process has been agreed. Supporting documentation and underpinning training is being developed. We aim to pilot the policy commencing August 2018. Our approach will be on a patient by patient basis. Patients will be highlighted to the GP by St Richard's Hospice Clinical Nurse Specialists. There will be ongoing review of this policy's use.

\section{P-123 THE OPIOID CONVERSION WORKBOOK: A NOVEL EDUCATIONAL INTERVENTION TO ENHANCE PATIENT SAFETY}

Robert Brodrick, Sylvia Reid. Sue Ryder Thorpe Hall Hospice, Peterborough, UK

10.1136/bmjspcare-2018-hospiceabs. 148

Background Proficiency in safely converting between opioids is an important skill for doctors and nurses working in palliative care. Rigorous opioid conversion training is rare (Webster, Bremner, Oosenbrug et al., 2017; Spitz, Moore, Papaleontiou 